Sallyann Colbert MB FFA, Deirdre M O'Hanlon MB FRCSI, Jacques Duranteau MD, Claude Ecoffey $M D$

\title{
Cardiac output during liver transplantation
}

Purpose: Measurement of cardiac output is an essential part of anaesthetic practice in patients undergoing major operative procedures. A thermodilution technique, using a pulmonary artery catheter is currently accepted as the gold standard in clinical practice. However its use is associated with several limitations.

Method: In this prospective randomised controlled study measurement of cardiac output, an oesophageal Doppler monitor (ODM) was compared with the thermodilution technique in 18 patients undergoing orthotopic liver transplantation. Measurements were taken during the three phases of liver transplantation, I) dissection phase (three measurements), ii) anhepatic phase (four) and iii) reperfusion phase (six).

Results: There were no differences observed between the two measurements at any of the times studied and a strong correlation was observed $(r=0.7 \mid 4 ; P<0.00001)$. However, when the data was analysed using Bland and Aitman analysis, while the mean difference was small $\left(0.07 \mathrm{l} \cdot \mathrm{min}^{-1}\right)$ it was $>21 \mathrm{~min} \mathrm{n}^{-1}$ in one third of measurements recorded i.e., the bias was near zero but the precision was large. No consistent differences were seen using the two methods in individual patients.

Conclusion: The use of the ODM results in cardiac output measurements which are considerably different from those obtained using thermodilution and its use cannot be recommended in patients undergoing orthotopic liver transplantation.

Objectif : La mesure du débit cardiaque est un élément essentiel de la pratique anesthésique chez les patients soumis à une procédure majeure. La technique de la thermodilution, utilisant un cathéter de l'artère pulmonaire, est actuellement la norme en pratique clinique, mais son utilisation connaît de nombreuses limites.

Méthodes : Au cours de cette étude prospective, contrôlée et aléatoire de mesure du débit cardiaque, un moniteur Doppler sesophagien a été comparé à la technique par hémodilution chez 18 patients sournis à une greffe hépatique. Des mesures ont été réalisées durant les trois phases de la greffe : 1 - dissection (3 mesures); 2- phase anhépatique ( 4 mesures); 3 - reperfusion ( 6 mesures).

Résultats : II r'y avait pas de différence entre deux mesures prises dans chacune des phases et une solide corrélation était observée $(r=0,7|4, P<0,0000|)$. Cependant, lorsqu'on analysait les données en utilisant le mode de Bland et Altman, on constatait que même si la moyenne des différences était petite $\left(0,07 \mid \cdot \mathrm{min}^{-1}\right)$, cette différence était de $>21 \cdot \mathrm{min}^{-1}$ dans le tiers des mesures, i.e., la précision était grande et le risque d'erreur faible. On ne trouvait pas de differences constantes chez un même patient en utilisant les deux méthodes.

Conclusion : L'utilisation du Doppler oesophagien donne des mesures du débit cardiaque qui sont considérablement différentes de ceiles obtenues par thermodilution et son utilisation ne peut être recommandée chez des patients subissant une greffe hépatique.

From the Department of Anesthesia and Intensive Care, Hôpital Paul Brousse, 16 Ave PV Couturier, 94800 Villejuif, France. Address correspondence to: Dr. Sallyann Colbert, Department of Anaesthesia, St James Hospital, Dublin 8, Ireland. Accepted for pubication November 9, 1997. 
M EASUREMENT of cardiac output in patients undergoing major surgery involving large haemodynamic changes is an essential part of anaesthetic practice. A thermodilution technique, using the Swan Ganz catheter is currently the method of choice. However there are well recognised limitations with this method. ${ }^{1-3}$ Insertion of a pulmonary artery catheter is required and this has an associated morbidity and mortality. The technique is costly, invasive, indirect, requires the participation of experienced personnel, takes time which may be better served elsewhere and it does not allow continuous monitoring. In addition, there are questions regarding the accuracy and precision of the measurements obtained. In spite of these drawbacks this technique is the best available and is widely accepted as the gold standard.

Many other techniques have been employed for assessing cardiac output, but all have limitations which make them impractical in the clinical setting. Oesophageal Doppler ultrasonography monitoring $(O D M)$ is one of these alternative techniques. While initially this technique was cumbersome and impracti$\mathrm{cal}$, advances in technology with the incorporation of a probe into a standard oesophageal stethoscope has revolutionised the technique. It provides continuous, inexpensive and relatively non invasive monitoring. It is easy to insert, requires little expertise to operate and is associated with negligible patient morbidity. ${ }^{4}$ The blood flow in the descending aorta is measured via a probe inserted into the oesophagus and a measurement of cardiac output is derived. ${ }^{4}$

Comparisons between these two methods of measuring cardiac output have been performed. Most studies demonstrate a good correlation between the techniques and suggest that while differences in actual measurements may be observed the ODM may be used to provide good continuous assessment of changes in cardiac output. . $^{5-9}$

Patients undergoing liver transplantation represent an unique group of surgical patients. The operative course is divided into three phases, dissection, anhepatic and reperfusion phases, each of which may be associated with marked changes in cardiac output. Comparison of these two methods for measuring cardiac output in this group of patients is an opportunity to compare the techniques.

This study was established to compare, prospectively, the Doppler technique of cardiac output measurement with the standard thermodilution technique in patients undergoing orthotopic liver transplantation.
Materials and methods

Eighteen patients undergoing semi-elective orthotopic liver transplantation were enrolled in the study. Parients with oesophageal varices (grade 22 ) and patients with fulminant hepatic failure were excluded from participation. Informed consent was obtained from all patients included in the study, in accordance with the guidelines laid down by the hospitals' Human Studies Committee.

Anaesthesia was induced with $0.1 \mathrm{mg} \cdot \mathrm{kg}^{-1}$ midazolam, $5 \mathrm{mcg} \cdot \mathrm{kg}^{-1}$ fentanyl and tracheal intubation was facilitated with $0.1 \mathrm{mg} \cdot \mathrm{kg}^{-1}$ pancuronium. A pulmonary artery catheter (\#7 French) was inserted into the right internal jugular vein. The balloon was inflated and the catheter was floated into the pulmonary artery under image intensification. Thermodilution cardiac output was measured by injecting $10 \mathrm{ml}$ ice cold dextrose $5 \%$ at end expiration by one individual (SC). The Edwards cardiac output computer was used to analyse the dilution curve and derive the cardiac output. Three measurements were made in rapid succession and the results were averaged.

The transoesophageal Doppler probe (Abbott Hospital, Rungis, France) was introduced following insertion of the pulmonary artery catheter. A disposable, lubricated, $6 \mathrm{~mm}, 4 \mathrm{MHZ}$ probe was passed orally until the tip was $35-40 \mathrm{~cm}$ from the incisors. At this level the oesophagus runs parallel to the descending thoracic aorta and spectral analysis of Doppler frequency shifts produced by blood flow in the aorta may be analysed via the Doppler ultrasound probe. The probe was manipulated and rotated on its long axis unvil a good signal was obtained. This was indicated by a good audible signal which coincided with the maximal signal on the digital display. The oesophageal monitor provided a continuous beat-by-beat audible and visual display of the cardiac output.

Liver transplantation is divided into three phases. The first, dissection phase, involves resection of the attachments of the diseased liver and preparation of the vascular structures for resection. The second, anhepatic phase, extends from the time the host liver is removed until the time the donor liver is revascularised. The reperfusion phase is the phase when the blood is circulating through the new organ and the biliary tree is reconstructed. During the dissection phase the cardiac output often decreases due to hypovolaemia and transient inferior vena cava compression. During the anhepatic phase the cardiac output decreases due to reduced venous return following clamping of the portal vein and inferior vena cava and the systemic vascular resistance increases. During the reperfusion phase, cardiac output may decrease considerably but usually transiently due to 
hyperkalaemia and the circulation of vasoactive metabolites. ${ }^{10}$ Following this, cardiac compensatory mechanisms result in restoration of the cardiac output.

In this study, 13 measurements of cardiac output were performed. Measurements were taken simultaneously in a random order using both techniques. Each measurement was performed in triplicate and the average measurement was obtained. A total of 234 paired measurements of cardiac output were recorded using the thermodilution method and the oesophageal Doppler probe. Three measurements were taken in the dissection phase, $30 \mathrm{~min}$ and $60 \mathrm{~min}$ after incision and five minutes before cross clamping. Four measurements were performed in the anhepatic phase, 5, 30 and $60 \mathrm{~min}$ after clamping and five minutes before unclamping. Six measurements were taken during the reperfusion phase, $1,2,3,4,5$ and $60 \mathrm{~min}$ after unclamping.

Statistical analysis was performed using the paired Students' $t$ test, the Wilcoxon signed rank test, Pearsons R, Spearman's correlation, linear regression analysis and Bland and Altman analysis ${ }^{11}$ with significance assumed at the $5 \%$ level.

\section{Results}

Eighteen patients undergoing semi-elective orthotopic liver transplantation were enrolled in the study. The age of the patients was $36.5 \pm 2.2 \mathrm{yr}$ (mean \pm SEM) and nine (50\%) were male. The weight of the patients was $60.2 \pm 1.7 \mathrm{~kg}$. The reasons for transplantation were: chronic active hepatitis five patients (28\%); primary biliary cirrhosis, three (17\%); sclerosing cholangitis, two $(11 \%)$; Wilson's disease, two (11\%); drug induced hepatic failure, two (11\%); alpha1 -antitrypsin deficiency, two (11\%); biliary atresia, one $(6 \%)$ and primary hepatic malignancy, one $(6 \%)$.

There were no differences between the measurements of cardiac output obtained when comparing both techniques at any of the 13 time periods studied. There was a correlation between the cardiac output measurements using both Pearsons test $(r=0.714$; $P<0.00001)$ and Spearman's correlation $(\mathrm{r}=0.735$; $P<0.00001$ ).

Using the Bland and Altman statistical method for assessing agreement between two methods of clinical measurement (Figure 1) the mean difference between the two measurements was small $\left(0.07 \mathrm{l} \cdot \mathrm{min}^{-1}\right)$, but the standard deviation of the difference was large $\left(2.1261 \cdot \mathrm{min}^{-1}\right)$. Over $68 \%(68.27 \%)$ of the differences between the paired values lay between the mean $\pm \mathrm{SD}$ of the difference and these limits were -2.06 to 2.19 $1 \cdot \mathrm{min}^{-1}$. Ninety-five percent of the differences between the paired values lay between the mean and $1.96 \times \mathrm{SD}$ for the difference and these limits were -4.10 to 4.23
$1 \cdot \mathrm{min}^{-1}$. These are referred to as the "limits of agreement" between the two different methods for measuring cardiac output (Figure 1).

Line graphs were drawn detailing the measurements obtained in all the patients at each of the periods studied. Each point plotted on these graphs represented the average of three measurements made with each of the methods at the time periods studied. In patient \#18, the two methods gave equivalent results at all the periods studied. In patient \#10 similar trends were seen with each method used but the ODM technique gave consistently higher readings than the dilutional method using the Swan Ganz catheter. In patient \#9 the dilutional method gave higher readings for cardiac output and while both methods gave similar results at the start of the study period, the difference between the readings increased and was $>21 \cdot \mathrm{min}^{-1}$ at the end of the study period. In patient \#6, no relationship was seen between the results obtained using the two techniques (Figure 2).

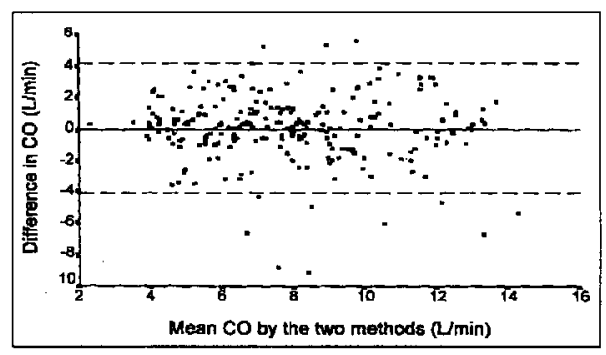

FIGURE 1 Bland and Altrman analysis of the paired sets of data.

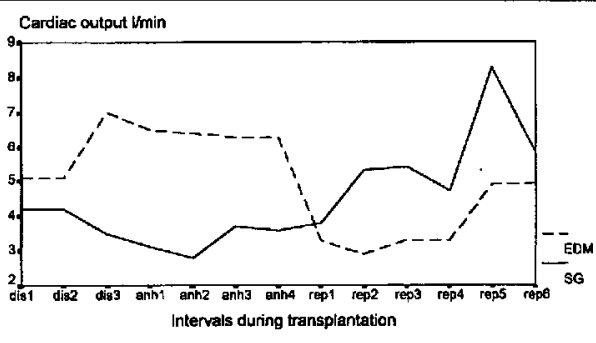

FIGURE 2 Graph showing serial cardjac output measurements in patient \#6.

Intervals during transplantation: Dis = dissection phase, Anh $=$ anhepatic phase, Rep = reperfusion phase. 


\section{Discussion}

Accurate and precise measurement of cardiac output is important in the anaesthetic management of major surgical cases. It guides fluid replacement and inotropic support and is an essential tool in the management of critically ill patients. Measurement of cardiac output using the thermodilution method is currently the gold standard in clinical practice. Unfortunately this, the most widely used method for assessing cardiac output is associated with considerable morbidity and has a well recognised mortality. ${ }^{1-3}$ Attention has now focused on alternative methods of measuring cardiac output. In the present study cardiac output was measured using oesophageal Doppler monitoring, a relatively non invasive method associated with a low morbidity, and this was compared with the standard thermodilution method using a pulmonary artery catheter.

Other studies have compared these two methods of measuring cardiac output. Most investigators have found good agreement between the methods. ${ }^{12}$ Lavandier et $a l^{13}$ found a high co-efficient of correlation between Doppler and thermodilution-measured cardiac output, although the absolute values were underestimated by the Doppler technique. Mark et al. ${ }^{7}$ found that the Doppler cardiac output tracked the thermodilution cardiac output accurately and proposed that the observed differences were mainly due to calibration errors. They suggested that it provided a good continuous assessment of changes in cardiac output and could be used as a trend monitor after calibration. Similarly, in the present study no differences were found between the mean values at any of the time periods examined and a highly significant correlation was found between the paired sets of data. In addition the mean of the differences between the paired data was extremely small.

When measurements of cardiac output are performed in triplicate, as in this study, changes of up to $15 \%$ are clinically acceptable. ${ }^{14-17}$ Could it be inferred that a difference up of $15 \%$ between these two techniques is also clinically acceptable? The mean cardiac outputs measured in this study ranged from 5.9 to 10.1 $1 . \mathrm{min}^{-1}$ and the " $15 \%$ limits" were $0.91(5.0-6.8$ $\left.1 . \mathrm{min}^{-1}\right)$ and $1.51\left(8.6-11.61 \cdot \mathrm{m}^{-1}\right)$ respectively. Using the Bland and Altman method" ${ }^{11}$ for assessing the agreement between different methods of clinical measurement, one third of cardiac output measurements differed by $>21 \cdot \mathrm{min}^{-1}$ while $5 \%$ of measurements differed by $>41 \cdot \mathrm{min}^{-\mathrm{l}}$. If the " $15 \%$ limits" are clinically acceptable, the differences observed between the two methods used is this study are unacceptable.

The cardiac output measurements were examined in individual patients. Good agreement was seen in some patients and, in others, trends were observed when comparing the two techniques. In other patients the results obtained were at variance and no standard pattern of variability was observed with cardiac output changing in an opposite direction using both of these techniques (Figure 2).

Kamal et al..$^{18}$ compared the ODM with a measurement of cardiac output using the Fick method in an animal model of acute haemorrhage. He found that the correlations between the two methods in individual animals varied from -0.76 to 0.98 and found an inconsistent association between the two methods both within and between individual animals. Wong et al ${ }^{19}$ examined cardiac output using thermodilution, ODM and transit time ultrasound and the latter was taken as the gold standard. Doppler cardiac output sensitivity was $62 \%$ and thermodilution cardiac output sensitivity was $79 \%$. When Doppler cardiac output increased $210 \%$, thermodilution cardiac output followed suit in $91 \%$ of cases. Doppler cardiac output changed in an opposite direction to the reference method in 6 out of 86 cases. Similarly thermodilution changed in an opposite direction in $5 \%$ of interventions. These studies call into question the accuracy and reliability firstly of the ODM and secondly, of thermodilution.

The thermodilution technique is accepted as the gold standard in clinical practice. Aside from morbidity associated with the use of the pulmonary artery catheter itself, this technique has a large number of drawbacks and has attained the status of "gold standard" almost by default through lack of suitable alternatives. There are questions regarding the accuracy of this technique because of poor reproducibility. Thrombus may form around the catheter and may occlude the proximal lumen resulting in false cardiac output measurements. ${ }^{20}$ Technical factors are important in obtaining accurate measurements and there are well defined intra-observer and inter-observer variations. Warming of the injectate may occur by handling the barrel of the syringe. A $1^{\circ} \mathrm{C}$ error in injectate temperature may result in a $2.8 \%$ error in measurement at $0^{\circ} \mathrm{C}$ while a similar error at room temperature may result in a $7.7 \%$ error. ${ }^{21}$ A $0.5 \mathrm{ml}$ error in bolus volume may result in a $10 \%$ error in cardiac output measurement. ${ }^{21}$ Too rapid an infusion may result in a $30-80 \%$ error and use of an incorrect computation constant can result in a $1-100 \%$ error. Measurement may be influenced by respiratory variations and differences of $20 \%$ may be seen in measurements taken at different stages of the respiratory cycle. ${ }^{22,23}$ As a result, measurements must always be performed in triplicate and errors of up to $15 \%$ are considered acceptable. ${ }^{17}$

There are many advantages associated with the use of the ODM: it is easy to insert, is relatively non- 
invasive and is operator independent. ${ }^{4}$ The continuous monitoring offered by this technique may result in more timely intervention in response to haemodynamic changes and facilitate improved patient management. Mark et al. ? $^{7}$ found that the coefficient of variation was considerably lower for ODM than for thermodilution.

However, there are disadvantages associated with the technique. The aortic diameter is estimated from an unvalidated nomogram which may introduce calibration errors. ${ }^{18}$ It is also assumed that blood flow in the descending thoracic aorta remains a fixed proportion of total left ventricular output. Approximately $75 \%$ of the cardiac output passes through the descending aorta and this proportion is little changed in high cardiac output states but it is variable in low cardiac output states where measurement of cardiac output is of particular importance. Doppler cardiac output underestimates changes in cardiac output due to changes in preload and contractility and exaggerates changes in cardiac output due to changes in afterload. ${ }^{19}$ It cannot be used in patients with oesophageal varices until cross clamping of the major vessels has been achieved. Intra-operative surgical manoeuvres as well as movements in the mediastinum frequently result in displacement of the probe necessitating adjustments.

In this study, comparing two methods of measuring cardiac output, clinically significant differences were observed between the two techniques. If the thermodilution method is accepted as the gold standard, the use of the ODM is not acceptable in patients undergoing orthotopic liver transplantation as the differences in measured cardiac output could lead to inappropriate intervention.

\section{References}

1 Connors $A F$, Speroff $T$, Dawson $N V$, et al. The effectiveness of right heart catheterization in the initial care of critically ill patients. JAMA 1996; 276: 889-97.

2 Sise MJ, Hollingsworth $P$, Brimm JE, Peters RM, Virgilio $R W$, Sbackford $S R$. Complications of the flow-directed pulmonary-artery catheter: a prospective analysis of 219 patients. Crit Care Med 1981; 9: 315-8.

3 Boyd KD, Thomas SJ, Gold J, Boyd AD. A prospective study of complications of pulmonary artery catheteriza tions in 500 consecutive patients. Chest 1983; 84: 245-9.

4 Singer $M$. Esophageal Doppler monitoring of aortic blood flow: beat-by-beat cardiac output monitoring Int Anaesthesiol Clin 1993; 31: 99-125.

5 Rose JS, Nanna M, Rabimtoula SH, Elkayam U, McKay C, Chandraratna PAN. Accuracy of determination of changes in cardiac output by transcutaenous continuous-wave Doppler computer. Am J Cardiol 1984; 54: 1099-101.
6 Huntsman LL, Stewart DK, Barnes SR, Franklin SB, Colocousis JS, Hessel EA. Noninvasive Doppler determination of cardiac output in man. Clinical validation. Circulation 1983; 67: 593-602.

7 Mark JB,Steinbrook $R A$, Gugino $L D$, et al. Continuous noninvasive monitoring of cardiac output with esophageal Doppler ultrasound during cardiac surgery. Anesth Analg 1986; 65: 1013-20.

8 Kumar A, Minagoe S, Thangatburai $D$, at al. Noninvasive measurement of cardiac output during surgery using a new continuous-wave Doppler esophageal probe. Am J Cardiol 1989; 64: 793-8.

9 Bernstein DP. Noninvasive cardiac output, Doppler flowmetry, and gold-plated assumptions (Editorial). Crit Care Med 1987; 15: 886-7.

10 Aggarwal $S, \operatorname{Kang} \Upsilon$, Freewan JA, Fortunato FL, Pinsky MR. Postreperfusion syndrome: cardiovascular collapse following hepatic reperfusion during liver transplantation. Transplant Proc 1987; 19(Suppl 3): 54-5.

11 Bland JM, Altman DG. Statistical methods for assessing agreement between two methods of clinical measurement. Lancet 1986; i :307-10.

12 Singer $M$, Clarke J, Bennett ED. Continuous hemody namic monitoring by csophageal Doppler. Crit Carc Med 1989; 17: 447-52.

13 Lavandier B, Cathignol D, Muchada R, Bui Xuan B, Motin J. Noninvasive aortic blood flow measurement using an intraesophageal probe. Ultrasound Med Biol 1985 ; 11: 451-60.

14 Vandermoten P, Bernard $R$, De Hemptinne J, Gillet JM, Lenaers $A$. Cardiac output monitoring during the acute phase of myocardial infarction: accuracy and precision of the thermodilution method. Cardiology 1977; 62: 291-5.

15 Kobanna FH, Cunningham JN Jr. Monitoring of cardiac output by thermodilution after open-heart surgery. J Thorac Cardiovasc Surg 1977; 73: 451-7.

16 Fischer $A P$, Benis $A M$, Jurado RA, Seely E, Teirstein $P$, Litwak RS. Analysis of errors in measurment of cardiac output by simultaenous dye and thermal dilution in cardiothoracic surgical patients. Cardiovase Res 1978; 12: 190-9.

17 Stetz CW, Miller RG, Kelly GE, Raffin TA. Reliability of the thermodilution method in the determination of cardiac output in clinical practice. Am Rev Respir Dis $1982 ; 125: 1001-4$.

18 Kamal GD, Symreng T, Starr J. Inconsistent esophageal Doppler cardiac output during acute blood loss. Anesthesiology 1990; 72: 95-9.

19 Wong DH, Watson T, Gordon I, et al. Comparison of changes in transit time ultrasound, esophageal Doppler, and thermodilution cardiac output after changes in preload, afterload, and contractility in pigs. Anesth Analg 1991; 72: 584-8. 
20 Bjoraker DG, Ketcham TR. Catheter thrombus artifactually decreases thermodilution cardiac output measurements. Anesth Analg 1983; 62: 1031-4.

21 Nishikawa $T$, Dobi S. Errors in the measurement of cardiac output by thermodilution. Can J Anaesth 1993; 40: 142-53

22 Snyder JV, Powner DJ. Effects of mechanical ventilation on the measurement of cardiac output by thermodilution. Crit Care Med 1982; 10: 677-82.

23 Stevens JH, Raffin TA, Mibm FG, Rosentbal MH, Stetz $C W$. Thermodilution cardiac output measurements. Effects of the respiratory cycle on its reproducibility. JAMA 1985; 253: 2240-2. 